Provided for non-commercial research and education use. Not for reproduction, distribution or commercial use.

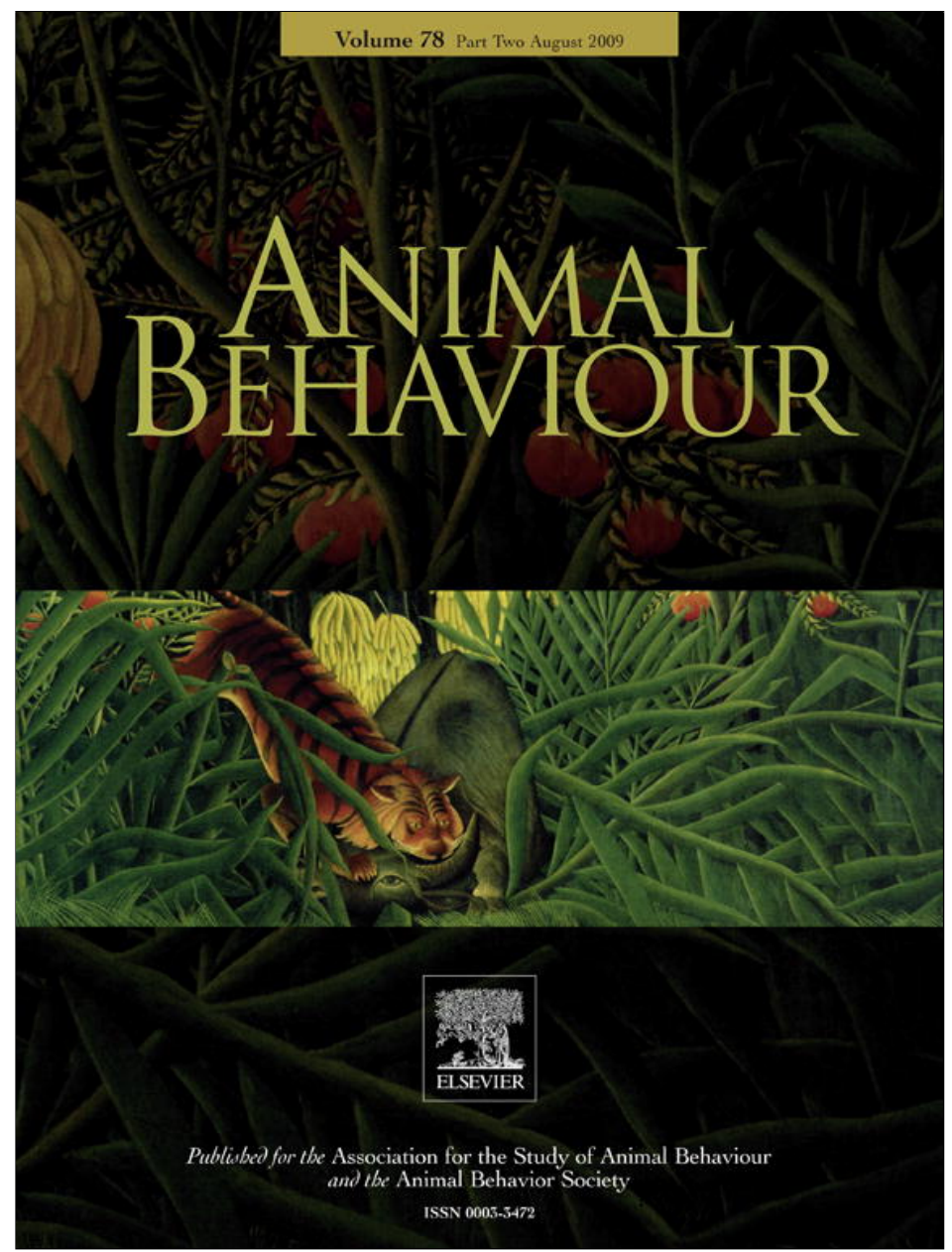

This article appeared in a journal published by Elsevier. The attached copy is furnished to the author for internal non-commercial research and education use, including for instruction at the authors institution and sharing with colleagues.

Other uses, including reproduction and distribution, or selling or licensing copies, or posting to personal, institutional or third party websites are prohibited.

In most cases authors are permitted to post their version of the article (e.g. in Word or Tex form) to their personal website or institutional repository. Authors requiring further information regarding Elsevier's archiving and manuscript policies are encouraged to visit:

http://www.elsevier.com/copyright 


\title{
Should I stay or should I go? Condition- and status-dependent courtship decisions in the scorpionfly Panorpa cognata
}

\author{
Leif Engqvist* \\ Department of Evolutionary Biology and Ecology, University of Bonn, Germany
}

\section{A R T I C L E I N F O}

\section{Article history:}

Received 5 December 2008

Initial acceptance 24 February 2009

Final acceptance 26 May 2009

Published online 11 July 2009

MS. number: 08-00771

\section{Keywords:}

courtship

female choice

nuptial gift

Panorpa cognata

precopula

scorpionfly

sexual selection
The occurrence of prolonged courtship behaviour in many animal species is a well-known phenomenon. The duration of courtship may be influenced by both females and males, often with different interests. In the scorpionfly Panorpa cognata, males offer a salivary secretion as a nuptial gift before copulation. However, males do not immediately initiate copulation by the production of the salivary mass. Instead pairs usually engage in prolonged courtship interactions. Yet the duration of courtship is highly variable, ranging between a few minutes and several hours. Furthermore, courtship does not always result in copulation; instead females often terminate courtship and abandon the male. The duration and outcome of courtship are likely to be influenced by factors such as body condition and female mating history, because they might influence individual attractiveness and motivation to mate. I examined to what extent these factors influence both male and female courtship decisions. Mated females were less keen to remain in courtship for long and abandoned males sooner than virgin females. Yet, male mating behaviour was unaffected by female mating status. Counterintuitively, females in poor condition interrupted courtship sooner with increasing body weight of their male partner. In addition, heavier males initiated copulations sooner than males in poorer condition. However, this effect was evident only in interactions with females in poor condition. A possible interpretation of these results is that males attempt to prevent females in poor condition from leaving prior to copulation by initiating copulation faster.

( 2009 The Association for the Study of Animal Behaviour. Published by Elsevier Ltd. All rights reserved.
In many animal mating systems, mating is preceded by courtship. Traditionally, the function of courtship was regarded mainly as a means for individuals to recognize species-specific traits to avoid erroneous sterile matings with individuals of other similar species (see Andersson 1994). However, there is now convincing evidence that male ornaments or traits displayed during courtship principally either serve as quality indicators to females and influence the choice of mates within a species (Johnstone 1995; Jennions \& Petrie 1997) or reflect male attempts to coerce females into mating, even if mating is not in the female's interests (Arnqvist \& Rowe 2005). Yet sometimes females are the courting sex; in many species with high paternal investment, ornamented females may court choosy males (Amundsen et al. 1997; Bonduriansky \& Brooks 1998; Bonduriansky 2001; Berglund \& Rosenqvist 2003) or both sexes may exercise mutual mate choice (e.g. Jones \& Hunter 1993; Kraak \& Bakker 1998). Similarly, in species with high male mating

\footnotetext{
* Correspondence and present address: L. Engqvist, Theoretical Biology Group, Centre for Ecological and Evolutionary Studies, University of Groningen, PO Box 14, NL-9750 AA Haren, The Netherlands.

E-mail address: l.m.engqvist@rug.nl
}

effort, for instance where males transfer a large sperm amount or produce costly nuptial gifts, time spent in courtship may potentially be used by males to assess female quality and determine how much to invest in this particular mating (Wedell et al. 2002).

In many species, courtship is brief and individuals make their choices relatively fast. However, in other species, pairs may engage in courtship or precopula for several hours or even days (Schaller 1971; Svärd \& Wiklund 1988; Jormalainen 1998; Proctor 1998; Engqvist \& Sauer 2002a), which prompts the question of what the adaptive significance of such behaviour is. In most reported examples of species with long-lasting precopula, males usually have almost exclusive control of the events (reviewed in Arnqvist \& Rowe 2005). In these cases, males are able to grasp females and guard them attentively until copulation, as has been reported for many crustaceans, spiders and insects (Svärd \& Wiklund 1988; Elwood \& Dick 1990; Watson 1991; Jormalainen 1998). The benefit for males is to delay mating until a more favourable time point. Females might, for instance, only be receptive for a short time (Elwood \& Dick 1990; Jormalainen 1998) or mating delay might reduce the risk of female remating and future sperm competition (Svärd \& Wiklund 1988). A male's decision to remain in copula will thus be affected by the time remaining to the most favourable time 
point for mating and the likelihood of finding a different female (Parker 1974; Grafen \& Ridley 1983). However, in species where female behaviour is not entirely under male control, females might directly influence the outcome by leaving (Schaller 1971; Proctor 1998; Engqvist \& Sauer 2002a), and in these cases males must also take female resistance and the likelihood of female departure into account (see for instance Jormalainen 1998).

An example of a long prelude to male pairing where female behavioural control is still maintained has been described for the scorpionfly Panorpa cognata (Insecta, Mecoptera; Engqvist \& Sauer 2002a). In this species, males attract females by emitting longrange pheromones as described for other scorpionflies (Thornhill 1979; Byers \& Thornhill 1983; Kock et al. 2007). Following the attraction of a female, copulation is not initiated immediately. Instead pairs engage in long courtship interactions. These are characterized by continuous male wing and abdominal movements and can last for several hours (Engqvist \& Sauer 2002a, 2003b). Yet females may leave at any point during this time. Eventually, the males initiate copulation by producing a salivary mass. Females feed on the salivary mass during copulation, and terminate copulation when they have consumed it. By producing a larger salivary mass before copulation, males increase copulation duration (Engqvist \& Sauer 2001), sperm transfer (Engqvist \& Sauer 2003a) and, thus, fertilization success (Engqvist et al. 2007), and also reduce the likelihood of female remating (Engqvist 2007c). Males produce and store saliva in their salivary gland. Saliva production is strongly dependent on male food intake and, correspondingly, is highly influenced by nutritional condition. In particular, foodlimited males have a very restricted amount of saliva in their glands (Engqvist \& Sauer 2001; Engels \& Sauer 2006) and may therefore be expected to invest these limited food resources cautiously (see Engqvist \& Sauer 2001, 2002b; Engqvist 2007a), similar to the expectation for prudent allocation of ejaculates (Dewsbury 1982; Wedell et al. 2002). Thus, the need for prudent male behaviour in terms of optimal mating investment may select for prolonged courtship, enabling males to evaluate female quality and willingness to mate.

Previous studies of $P$. cognata have shown that the variance in the duration of the premating associations is immense, ranging from a few minutes to almost 7 h (Engqvist \& Sauer 2002a, 2003a; Engqvist 2007a). It has been repeatedly found that premating duration to a large extent is explained by male body condition: males in good condition initiate copulations faster (Engqvist \& Sauer 2002a, 2003a). Yet, the initiation of copulations seems to be a hazardous event as the costly nuptial gift is sometimes rejected. The nuptial gift is more likely to be accepted by the female if premating duration is long (Engqvist \& Sauer 2002a). Nevertheless, if males wait too long, courtship is more likely to be interrupted and the female will abandon the male (Engqvist \& Sauer 2002a). In fact, the majority of females do not remain in courtship for long and will thus represent missed opportunities for males that hesitate.

These findings inspired Engqvist \& Sauer (2002a) to propose a novel hypothesis for the evolution of long premating associations. Males in poor condition with a limited supply of saliva may deliberately delay initiating copulations to decrease the probability that their costly gift is rejected and, thus, wasted. Males in good condition with ample mating resources, on the other hand, may afford the risk of wasting a salivary mass and therefore take every opportunity to mate.

These previous studies have concentrated on male promptness in producing and offering saliva as a nuptial gift, thereby focusing on only those interactions in which males actually offer saliva. Consequently, nothing is yet known regarding female willingness to remain for long in courtship waiting for male salivary mass production. In addition to focusing on male decisions, this study is thus a first attempt to understand variation in female waiting duration.

Female readiness to remain in long-lasting courtship interactions with males will be a result of different processes (Brooks \& Endler 2001; Reinhold et al. 2002), each with its own set of predictions. Female feeding history and mating status might influence female responsiveness (i.e. motivation to mate), female choosiness (i.e. whether to prefer certain males) and female preference (which male to prefer). As females receive both sperm and nutrients during mating (Engqvist 2007b), females with different mating and feeding histories may differ in their general motivation to remain in courtship. Nonmated females will be more dependent on the provision of sperm during copulation than already mated females, and might therefore be more persistent. Food-stressed females will, compared to well-fed females, be more reliant on the nuptial gifts provided before copulation and therefore show higher mating responsiveness. However, well-fed females will have developed more eggs than poorly fed females (Engqvist \& Sauer 2001, 2003a), and, if they have not mated, they might even be more eager to mate in order to oviposit soon. Thus, there is no clear-cut expectation on the effect of female feeding history on female responsiveness and willingness to remain for long in courtship. Furthermore, females with different feeding histories and conditions might differ with respect to their choosiness and preference for certain males (Bakker et al. 1999; Cotton et al. 2006). For instance, if female mating opportunities are restricted (e.g. because of the cost of sampling or mating), food-stressed females might be expected to be more discriminating and mate preferentially with those males that provide the largest, most nutritious gifts (e.g. Bussière et al. 2005; Lehmann \& Lehmann 2008), that is with males in good condition (Engqvist \& Sauer 2001). Yet if females can mate with many males, it might be better for females in poor condition to mate indiscriminately to maximize the rate at which they obtain male-provided nutrients (Brown 1997). Again there is no straightforward prediction regarding the effect of female feeding history on female choosiness.

In this study I manipulated male feeding history and, in two separate experiments, female feeding history and female mating status, respectively. I analysed both how male readiness to offer the gift fast and how female willingness to remain in courtship were influenced by female mating status along with female and male condition. Adult feeding history will in some way affect the body condition of males and females, and although the term condition is often used as a more general term (e.g. Rowe \& Houle 1996), here it refers to the dietary history of individuals.

\section{METHODS}

\section{Breeding Conditions}

Adult scorpionflies used in both experiments all descended from wild-caught animals collected near Freiburg i. Br. in southwestern Germany. In the first experiment, I used $F_{1}$ or $F_{2}$ offspring from animals collected in August 2003 or May 2004. In the second experiment, I used $F_{1}$ offspring from animals collected in May 2003. In both experiments, established standard breeding protocols for scorpionflies were used (see Sauer 1970, 1977; Thornhill \& Sauer 1992; Engqvist \& Sauer 2003a for details). Larvae were reared in petri dishes (diameter: $12 \mathrm{~cm}$ ) in groups of up to 20 at $18{ }^{\circ} \mathrm{C}$ on an 18:6 h light:dark regime inducing diapause-free development (e.g. Sauer 1970). Petri dishes contained moist filter paper and were supplied with small segments of mealworm (Tenebrio molitor) ad libitum. Once larvae had reached the third larval stage, they were transferred outdoors to soil-filled, open-bottom cylinders (diameter: $40 \mathrm{~cm}$; depth: $1 \mathrm{~m}$ ) that were placed in the ground. Here they 
were further fed on a diet consisting of small pieces of mealworms until pupation.

\section{Influence of Female and Male Body Condition}

On the day of adult emergence from the outdoor breeding containers (beginning of August 2004), both females and males were randomly assigned to different treatments affecting nutritional status. Females were assigned to two different treatments. From day 1 until the courtship trials (beginning on day 15), they were either fed every third day (good nutritional condition) with a segment of a mealworm or every sixth day only (poor nutritional condition). These are well-established treatments for creating two distinct classes of condition in this species (Engqvist \& Sauer 2001, 2003a). Condition was estimated as the difference in weight between the time of the mating trial and the day of adult emergence. Four females in the poor-condition treatment gained more weight than some of the females in the good-condition treatment and were therefore excluded from the analyses presented here (see also Engqvist 2007d). Including them did not qualitatively change the results. The mean \pm SD weight of the females in poor condition amounted to $39.20 \pm 2.95 \mathrm{mg}$ (range $32.6-43.4 \mathrm{mg}, N=64$ ) and that of females in good condition to $52.40 \pm 3.96 \mathrm{mg}$ (range 46.4$62.3 \mathrm{mg}, N=61$ ). Values of this magnitude are not uncommon in natural populations (L. Engqvist, unpublished data). The mean \pm SD condition (weight gain) for the females in poor condition was $11.19 \pm 2.92 \mathrm{mg}$ (range $4.5-15.8 \mathrm{mg}$ ) and $25.06 \pm 4.26 \mathrm{mg}$ (range $16.7-34.2 \mathrm{mg}$ ) for the females in good condition. Males, on the other hand were fed either every third, fourth, fifth or seventh day. Yet, the weight differences between these male groups were much smaller than those between female groups, with substantial overlap in the weight distributions of groups. In the analyses, I therefore treated male condition as a continuous variable instead of a discrete variable with four levels. From emergence until the trials, animals were kept individually in small plastic tubes $(8 \times 3.5 \mathrm{~cm})$ containing moist filter paper and food. As age influences premating duration (Engqvist \& Sauer 2002a), this and the following experiment were all done with individuals of similar age (14-17 days) that had all reached sexual maturity (approximately 10-12 days; see also Engqvist \& Sauer 2003b).

\section{Influence of Female Mating Status}

In this experiment, females were randomly assigned to one of two treatments: either the female had already mated before or the female was virgin at the time of the courtship trial. Courtship trials of mated females were performed on the first day following their first mating. All females and males used in this experiment were in good nutritional condition, and had received a mealworm segment every third day.

\section{Courtship Trials}

All courtship trials were staged in transparent plastic boxes $(10 \times 10 \mathrm{~cm}$ and $7 \mathrm{~cm}$ high) containing moist filter paper. In addition, as $P$. cognata prefer to mate on the underside of leaves, nettle plants, Urtica dioica, were cut at each internode, and all mating boxes were provided with a minute vessel containing one of these miniature nettle plants and water.

Panorpa cognata is crepuscular and nocturnal in its mating activities like many other Panorpa scorpionflies (Byers \& Thornhill 1983; Engqvist \& Sauer 2003b; Kock et al. 2007). Females approach pheromone-emitting ('calling') males almost exclusively during the last hours prior to nightfall (Engqvist \& Sauer 2003b; see also Kock et al. 2007). I therefore did the experiments under a reversed day/night cycle (see e.g. Engqvist \& Sauer 2003b). Trials started approximately $4 \mathrm{~h}$ (at 0800 hours) prior to the dark phase. Male calling activity usually stops abruptly when it gets dark and courtship is very rarely initiated after this time. I therefore interrupted mating trials $2 \mathrm{~h}$ after the beginning of the dark phase when all calling had ceased, unless females had approached a male at that time point. Hence, every experimental day females had $6 \mathrm{~h}$ to approach a male for courtship to begin, but courtship could continue for much longer. Trials that were interrupted after $6 \mathrm{~h}$ because no courtship had begun were repeated the next day.

First, males were allowed to enter the mating boxes. After a few minutes of acclimatization, a female was carefully put in each box and the boxes were continuously observed. Most importantly, the time when a female was attracted to a male and courtship began was noted. In all experiments, courtship was defined to begin when females were standing closer than $5 \mathrm{~mm}$ to the male. Males then almost invariably stop 'calling' by reverting the pheromonal gland and instead commence their typical courtship movements. Males usually display by moving their abdomen up and down in a pulsating, rhythmical fashion, accompanied by vibrating wing movements (Engqvist \& Sauer 2003b; Engqvist 2007d). Thereafter, the time when courtship ended was noted: either the female left the male or the male produced a salivary mass.

\section{Statistical Analysis}

This study was concerned with two main questions. The first relates to factors influencing the time females are prepared to remain in courtship, that is, the time between the beginning of courtship and female departure. The second concerns the prelude duration before males secrete and offer females a salivary mass as a nuptial gift. Unfortunately, it was not possible to estimate these parameters exactly for all mating trials. For instance, in many trials it was not feasible to measure exactly the time to female departure because females did not leave the males, but waited until the males produced a salivary mass and copulated. Yet, it would be a profound mistake to discard these data from the analysis as they are probably nonrandomly distributed and in any event provide important information (not the exact time until female departure, but the minimum time until female departure). Therefore, survival analyses (also called failure-time analyses) were carried out, which allowed me to enter these data as censored observations (e.g. Fox 2001; Therneau \& Grambsch 2004). Thus, in questions regarding female departure, observations were right censored at either the time copulations started or when I interrupted courtship (two cases), meaning that a data point was certain to be above a certain value but it was unknown by how much. Theoretically, it would also have been possible to enter cases where males interrupted courtship and left the female as censored data, but this never happened during these experiments. Similar analyses were used to analyse the duration of courtship before males secreted a salivary mass. Here, however, observations were censored at the time of female departure or the time of my interruption. Thus, female departure behaviour was analysed independently from male salivary secretion behaviour. In interactions where females did leave prematurely, the exact data for females' departure time and the minimum (censored) time until salivary secretion could be extracted. In interactions where males produced a salivary mass, the exact durations until male secretion and the minimum (censored) female waiting times were available. These analyses make it possible to disentangle female departure time from male saliva production time statistically. But we still have to bear in mind that it will always remain difficult to know the extent to which, for instance, female courtship decisions are affected by male actions. Although males do not interrupt courtship, they might put less 
effort into it and therefore indirectly influence female courtship interruption.

All analyses were performed using R 2.8.0 (R Development Core Team 2008). Cox proportional hazards models were performed using the coxph function of the survival library (Therneau \& Grambsch 2004). The statistical significance of model parameters was tested using the change in log likelihood which follows a chisquare distribution.

\section{RESULTS}

\section{Influence of Female and Male Condition}

In this experiment, I observed the outcome of 125 female-male interactions: 61 involved a female in good nutritional condition and 64 a female in poor nutritional condition. In 61 (48.9\%) interactions, a mating occurred after $117.1 \pm 109.1 \mathrm{~min}$. In the analysis of time until female courtship termination, there was a significant interaction between female treatment and male condition (Fig. 1) on the survival function $\left(\chi_{1}^{2}=9.89, P=0.002\right)$, indicating that the effect of male condition was different in the two female groups. For females in poor condition, male condition had a significant influence on time until female courtship termination $(\beta \pm \mathrm{SE}=0.099 \pm 0.041$, $\chi_{1}^{2}=5.89, P=0.02$; Fig. $1 \mathrm{a}$ ), whereas for females in good condition male condition did not influence the chances of female departure $\left(\beta \pm \mathrm{SE}=-0.054 \pm 0.042, \chi_{1}^{2}=1.90, P=0.2 ;\right.$ Fig. $\left.1 \mathrm{~b}\right)$. For females in poor condition, the value of the estimated coefficient describing the effect of male condition on the hazard function was positive, implying that increased male condition is associated with an increased failure rate and thus interactions of shorter duration. Thus, females in poor condition interrupted courtship sooner in interactions with heavier males than when lighter males were courting them (Fig. 1a).

Similarly, the time until the male offered a salivary mass was best explained by an interaction between female treatment and male condition $\left(\chi_{1}^{2}=5.57, P=0.02\right)$. As for female departure, male condition significantly influenced the time until salivary mass offering in interactions with females in poor condition $\left(\beta \pm \mathrm{SE}=0.125 \pm 0.045, \chi_{1}^{2}=6.97, \quad P=0.008\right.$; Fig. $\left.2 \mathrm{a}\right)$ : heavier males produced the nuptial gift sooner than males in poorer body condition. Yet, in courtship with females in good condition male condition had no significant effect on the promptness of salivary mass production $\left(\beta \pm \mathrm{SE}=-0.0005 \pm 0.029, \chi_{1}^{2}=0.0003, P=0.98\right.$; Fig. 2b).

\section{Influence of Female Mating Status}

In this experiment, I observed 278 male-female interactions: 224 with virgin females and 54 involving once-mated females. Copulations occurred in 159 (57.2\%) cases after on average $79.0 \pm 76.0 \mathrm{~min}$. Female and male weights were used as covariates. In the first maximal model all higher order interactions including the three-way interaction were entered. In the analysis of time until female departure, none of the higher-order interactions were significant (all $\chi_{1}^{2}<3.34$, all $P>0.05$ ) and were therefore stepwise removed from the model (see Aiken \& West 1991; Engqvist 2005). Female mating status significantly influenced time until female courtship termination (Table 1). Mated females left the courting male significantly sooner than virgin females (Fig. 3a, Table 1). Female and male weight were entered as covariates, but had no significant effect (Table 1 ).

In the analysis of time until male production of a salivary mass, all higher-order interactions were nonsignificant (all $\chi_{1}^{2}<1.14$, all $P>0.05)$ and were therefore removed from the model. Yet, unlike the previous analysis, female mating status had no effect on

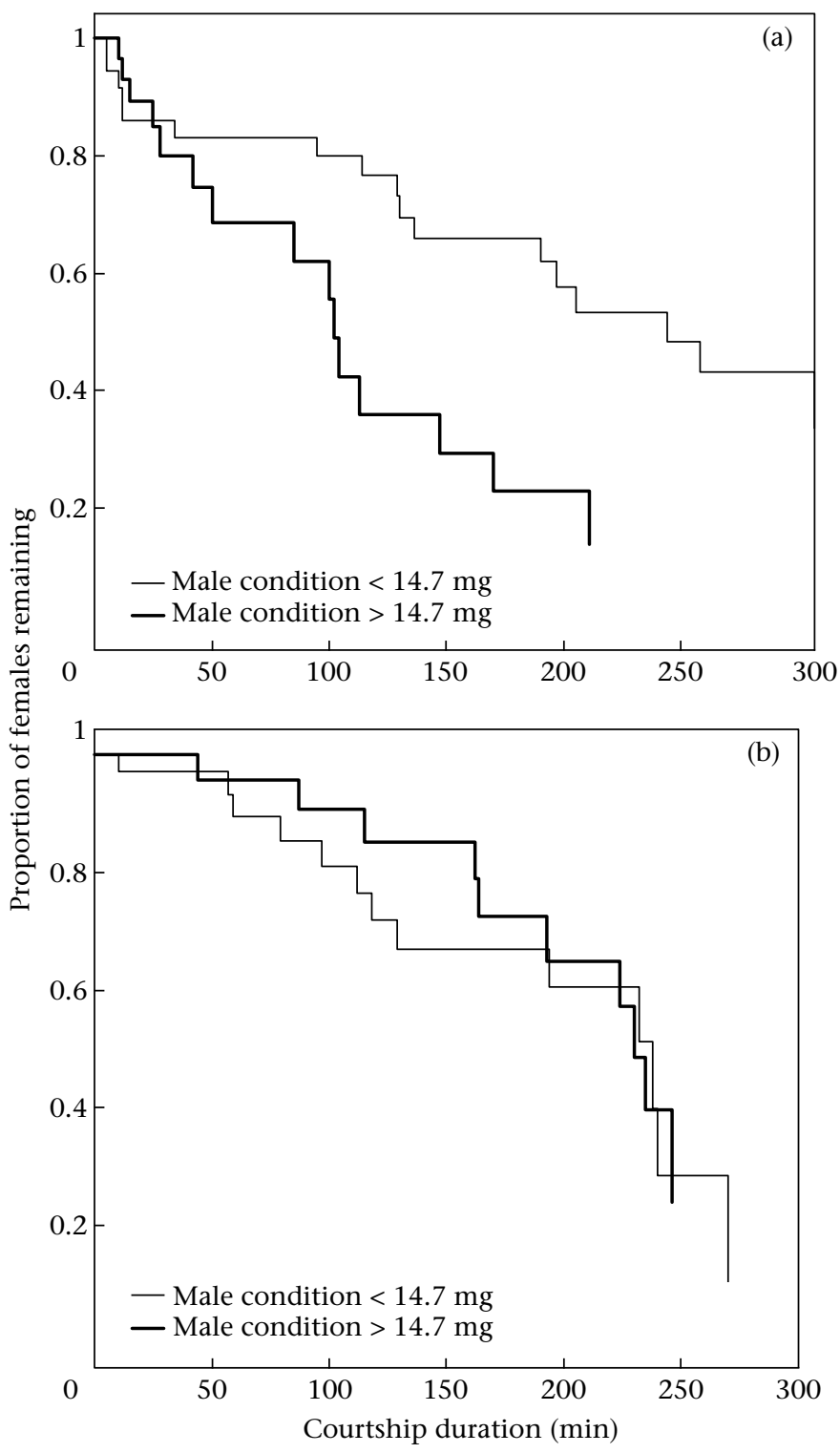

Figure 1. Survival curves showing the proportion of females remaining with the male as a function of courtship duration for (a) females in poor condition and (b) females in good condition. The separate lines illustrate the effect of male condition. The bold lines show the survival curves for courtship interactions involving males in good condition with body condition above the median ( $>14.7 \mathrm{mg}$ weight gain), whereas the thin lines represent the survival curves for courtship interactions involving males in poor condition, below the median. The classification of males into two groups was made for illustrative purposes only; in all analyses male condition was handled as a continuous variable.

courtship duration until male copulation initiation (Fig. 3b, Table 1). As in the previous analysis, female and male weights were entered as covariates, but had no significant effect (Table 1).

\section{DISCUSSION}

Courtship duration in the scorpionfly $P$. cognata is influenced by two different processes: female willingness to remain in courtship and the promptness of male salivary mass production initiating mating. In two experiments, I investigated whether these two processes are affected by female mating status as well as by female and male condition. The results of these experiments demonstrate that female willingness to stay was at least to some extent 

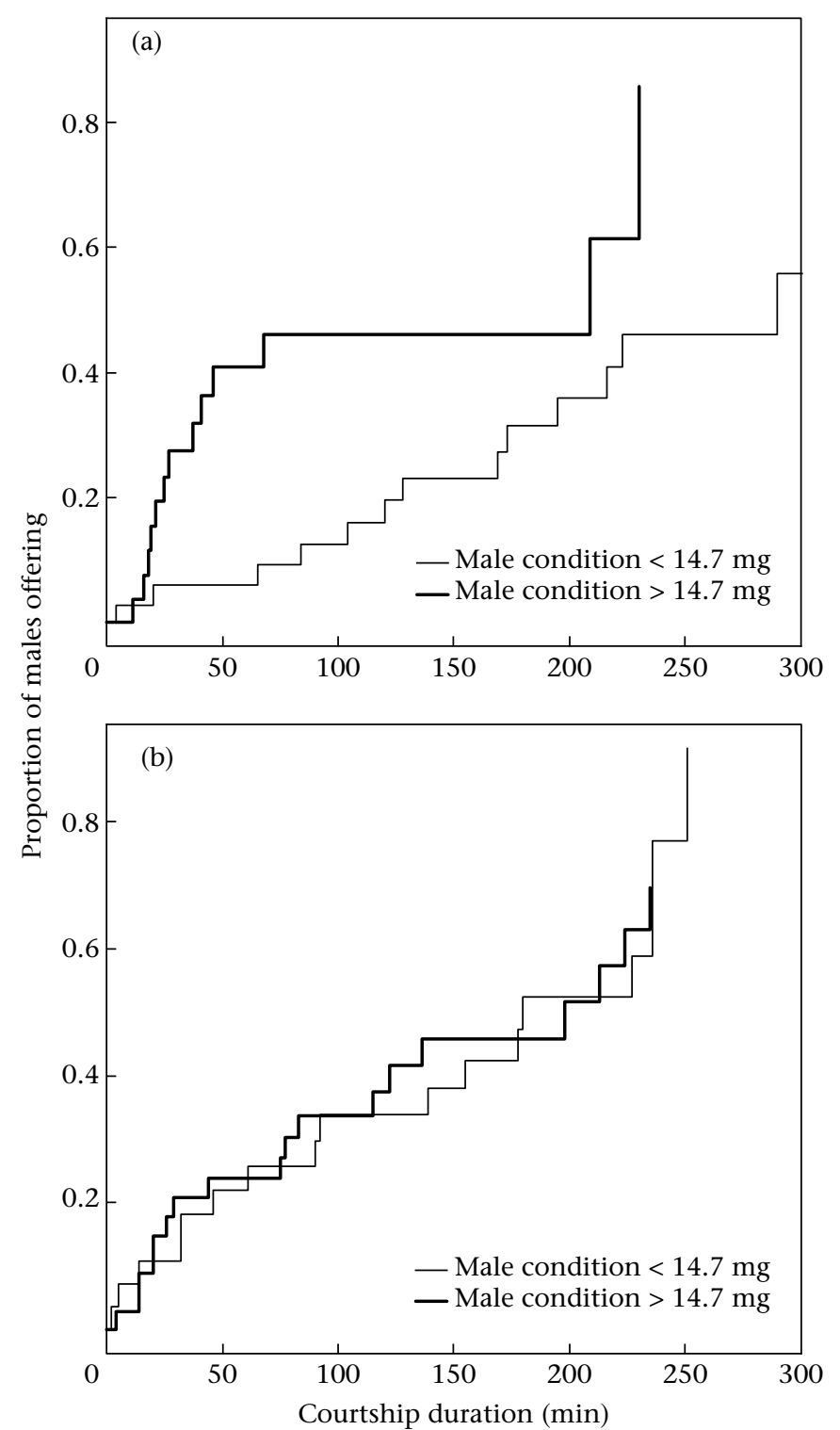

Figure 2. Cumulative time-to-event plots showing the proportion of males initiating mating by offering a salivary mass as a function of courtship duration in interactions with (a) females in poor condition and (b) females in good condition. As in Fig. 1, the separate lines illustrate the effect of male condition. The bold lines show the survival curves for courtship interactions involving males in good condition with body condition above the median ( $>14.7 \mathrm{mg}$ weight gain), whereas the thin lines represent the survival curves for courtship interactions involving males in poor condition, below the median. The classification of males into two groups was made for illustrative purposes only.

influenced by female mating status and by a combination of their own body condition and that of their male partner. Male salivary mass production, on the other hand, was not influenced by female mating status. Yet in a similar pattern to female willingness to remain, a combination of male and female body condition seemed to affect male behaviour.

\section{Influence of Female and Male Body Condition}

In particular, the results from the experiment testing the effects of male and female condition on male and female courtship decisions seem difficult to grasp. Females in poor condition were more likely to interrupt courtship interactions with heavy males than
Table 1

Summary of the survival analyses on the effect of female mating status and female and male condition on both the time until female departure and the courtship duration until male copulation initiation

\begin{tabular}{|c|c|c|c|c|c|c|}
\hline \multirow[t]{2}{*}{ Predictor variables } & \multicolumn{3}{|c|}{$\begin{array}{l}\text { Time until female } \\
\text { departure }\end{array}$} & \multicolumn{3}{|c|}{$\begin{array}{l}\text { Time until male copulation } \\
\text { initiation }\end{array}$} \\
\hline & $\beta \pm S E$ & $\chi_{1}^{2}$ & $P$ & $\beta \pm S E$ & $\chi_{1}^{2}$ & $P$ \\
\hline Female mating status & $0.592 \pm 0.229$ & 6.0 & 0.01 & $0.089 \pm 0.229$ & 0.09 & 0.72 \\
\hline Female condition $(\mathrm{g})$ & $-16.7 \pm 15.1$ & 1.1 & 0.29 & $-15.6 \pm 12.7$ & 1.59 & 0.21 \\
\hline Male condition (g) & $-2.10 \pm 17.4$ & 0.0 & 0.92 & $-3.91 \pm 14.5$ & 0.09 & 0.78 \\
\hline
\end{tabular}

Cox proportional hazards regression models were used. The $\beta$ values give the coefficients for the estimated hazard function. For covariates, positive values of $\beta$ indicate a shorter average time-to-event (increased hazard) with higher values of the predictor variable. For female mating status, the $\beta$ values give the log hazard ratios between groups. A positive $\beta$ value indicates an increased hazard and a shorter time-to-event for mated females. All first- and higher-order interactions were nonsignificant and removed prior to the final analyses (see text).

with light males (Fig. 1a). In two respects this outcome was highly unexpected. First, one would expect that if females exercise mate choice, then they would prefer males in good condition (Andersson 1986; Rowe \& Houle 1996) and would not leave sooner when courted by them. Second, one would normally not expect females in poor condition to be more choosy, as usually higher-quality individuals should afford to be more selective (Johnstone et al. 1996; Cotton et al. 2006). Yet if females mate infrequently, females in poor condition that depend more on nutritious nuptial gifts might be expected to be more discriminating. However, this possible explanation is unlikely to explain the results, as female P. cognata are rather polyandrous (Engqvist \& Sauer 2003b), and it therefore seems more beneficial for females in poor condition to be undiscriminatiing and mate with as many males as possible (e.g. Brown 1997). Another possibility is that females in good condition with higher egg load might be more eager to mate to start egg laying and therefore be more sexually responsive (Hunt et al. 2005). Yet this explanation ignores the fact that females in good and poor condition did not differ much in their response to males in poor condition (compare the thin lines in Fig. 1a, b). Thus, it does not really address the question of why females in poor condition seem to discriminate specifically against good-condition males.

Interactions where males in good condition courted females in poor condition were also characterized by unusually fast male salivary mass offering and copulation initiation (Fig. 2a). Males in good condition initiate copulations sooner than males in poor condition (Engqvist \& Sauer 2002a, 2003b), but why would this effect be most pronounced in interactions with females in poor condition? One possibility could be that to take advantage of the mating opportunity, males have to forestall female departure and initiate copulations quickly. Comparing Figs 1a and 2a reveals that, in interactions between heavy males and females in poor condition, male mating attempts occurred predominantly within the first hour following courtship initiation (Fig. 2a): concurrently an increased frequency of female departure events occured at a courtship duration of 75-100 min, later than most offering attempts (Fig. 1a). Females in poor condition may thus be responsive at an early stage in courtship. Yet male reluctance to initiate copulation within the first hour of courtship may signal male disinterest to females and it may be better to leave at this time point. This might be reflected in the increased likelihood of female departure. The major problem, though, with this explanation is that the benefit of both behavioural phenomena depends on the existence of each other. Thus, the conditions for the evolution of this combination of gender-specific behaviour should be constrained. Nevertheless, with the current knowledge of this mating system, the scenario outlined above at least seems a reasonable working hypothesis for future research. 

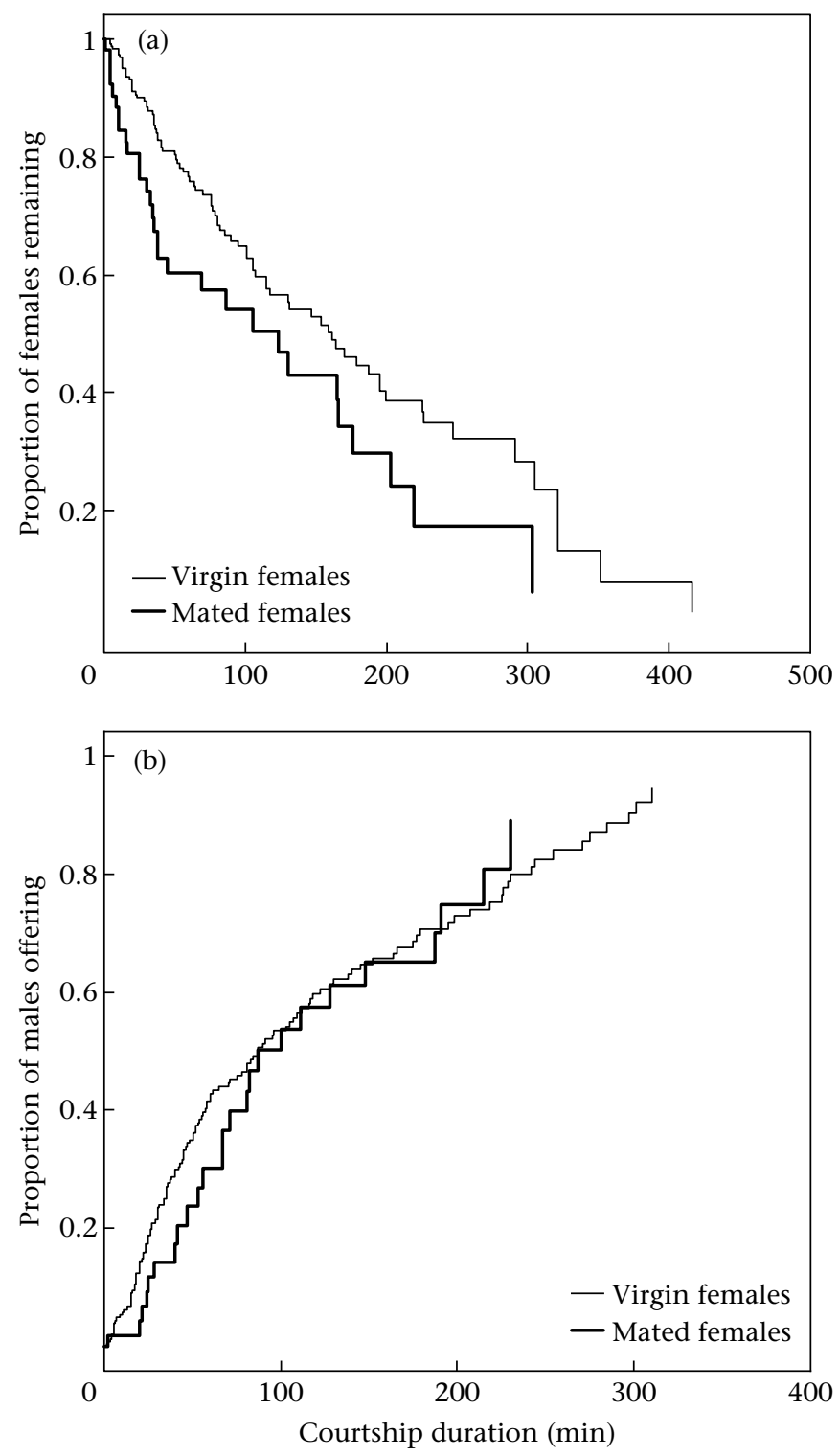

Figure 3. The effect of female mating history on courtship duration illustrated by (a) the survival curves showing the proportion of females remaining with the male as a function of courtship duration and (b) the cumulative time-to-event plot showing the proportion of males initiating mating by offering a salivary mass as a function of courtship duration. The outcome of courtship interactions with mated females are represented by solid lines and interactions with virgin females are represented by thin lines.

An alternative explanation is that sexual conflict has driven the evolution of male and female preferences (reviewed in Arnqvist \& Rowe 2005). There is some indication that in P. cognata, malederived substances in the salivary masses enable males to manipulate female remating and reproduction (Engqvist 2007c). It is at least possible that males in good condition might be particularly potent manipulators and thus more harmful to females. In addition, females in poor condition might be more sensitive to males. In this case, it might even be beneficial for males to prefer females in poor condition. At the same time, females in poor condition should avoid matings with males in good condition.

\section{Influence of Female Mating Status}

The most straightforward result of this study was that mated females were less likely than virgin females to remain in courtship, waiting for the male to initiate copulation. Mated females would benefit from additional matings because of nuptial gift consumption (Engqvist 2007b), although these nutritional benefits may not always outweigh the costs of enduring a long-lasting courtship interaction. In a recent study, experimental mating trials with mated females were less likely to result in copulations than mating trials involving virgin females (Engqvist 2007c). The present results confirm these findings and suggest that the reduced success of mating attempts with mated females can at least partly be explained by their reduced motivation to remain in courtship for long. In addition, mated females may also be less likely to seek and be attracted to 'calling' males, but this possibility remains to be studied. Mating-induced changes in female reproductive behaviour have been widely documented in insects (see Leopold 1976; Chapman et al.1998; Wedell 2005). Reduced receptivity following mating may be induced by an adequate sperm supply (Wedell 2005), but other male-produced compounds transferred during copulation are known to induce female receptivity (Leopold 1976; Chapman et al. 1998; Wedell 2005), possibly as a male adaptation to reduce the risk and intensity of sperm competition (Parker \& Simmons 1989; Simmons \& Gwynne 1991; Stockley 1997). In P. cognata, the reduced receptivity following mating is at least partly mediated by salivary mass consumption during mating (Engqvist 2007c), which may either indicate that the saliva secretions are instruments for male manipulation of female mating behaviour or that optimal female mating frequency is influenced by salivary mass consumption (see discussion in Engqvist 2007c; Gwynne 2008).

In contrast to the behaviour of females, male courtship behaviour was not influenced by the mating status of the female. The most straightforward explanation is that males are simply unable for assess female mating status. Yet there is good evidence that males invest strategically in matings in relation to the amount of sperm stored by females from previous matings (Engqvist 2007a). Thus, males seem capable of a very precise assessment of female mating history. Male inability to assess female mating status therefore appears unlikely as an explanation for these results. One might expect males to prefer virgin females and initiate matings sooner with them, because, as a result of sperm competition, the reproductive value of copulating with mated females will on average be less than the value of mating with nonmated females (Simmons et al. 1994; Bonduriansky 2001). In contrast, as mated females are less likely to remain for long in courtship, males could also be expected to initiate copulations quickly to take advantage of the mating opportunity before courtship is interrupted by the female. Yet none of these possibilities were supported by the data. Possibly, for instance, search costs related to finding future prospective mates may set constraints on male preferences (Real 1990; Milinski \& Bakker 1992).

This study on courtship duration in scorpionflies revealed some unexpected, yet interesting results. It is obvious that to understand courtship decisions fully, one will need an even better insight into the different behavioural elements displayed by both females and males during courtship and what they signal. Future studies should therefore examine how, for instance, eagerness to mate and choosiness are reflected in different behavioural elements. The results also emphasize that to make theoretical predictions of the optimal male waiting duration in courtship interactions without complete male control, it is necessary to take female behaviour into account and vice versa (Jormalainen 1998). Such considerations will not only be relevant for this particular mating system. In fact, long precopula behaviour in species where females are able to disrupt courtship is not uncommon but seems especially common in soil arthropods with indirect sperm transfer (Schaller 1971; Proctor 1998), where a very similar courtship behaviour has evolved. 


\section{Acknowledgments}

I was funded by the Deutsche Forschungsgemeinschaft (EN 469/ 1-1). Julia Leven helped in the laboratory with the rearing of scorpionflies. Joachim Frommen and Klaus Reinhold, Nils Anthes and an anonymous referee gave helpful criticism on the manuscript.

\section{References}

Aiken, L. S. \& West, S. G. 1991. Multiple Regression: Testing and Interpreting Interactions. Newbury Park: Sage Publications.

Amundsen, T., Forsgren, E. \& Hansen, L. T. T. 1997. On the function of female ornaments: male bluethroats prefer colourful females. Proceedings of the Royal Society B, 264, 1579-1586.

Andersson, M. 1986. Evolution of condition-dependent sex ornaments and mating preferences: sexual selection based on viability differences. Evolution, 40, 804-816.

Andersson, M. 1994. Sexual Selection. Princeton, New Jersey: Princeton University Press.

Arnqvist, G. \& Rowe, L. 2005. Sexual Conflict. Princeton, New Jersey: Princeton University Press.

Bakker, T. C. M., Künzler, R. \& Mazzi, D. 1999. Condition-related mate choice in sticklebacks. Nature, 401, 234

Berglund, A. \& Rosenqvist, G. 2003. Sex role reversal in pipefish. Advances in the Study of Behavior, 32, 131-167.

Bonduriansky, R. 2001. The evolution of male mate choice in insects: a synthesis of ideas and evidence. Biological Reviews, 76, 305-339.

Bonduriansky, R. \& Brooks, R. J. 1998. Male antler flies (Protopiophila litigata; Diptera: Piophilidae) are more selective than females in mate choice. Canadian Journal of Zoology, 76, 1277-1285.

Brooks, R. \& Endler, J. A. 2001. Female guppies agree to differ: phenotypic and genetic variation in mate-choice behavior and the consequences for sexual selection. Evolution, 55, 1644-1655.

Brown, W. D. 1997. Female remating and the intensity of female choice in blackhorned tree crickets, Oecanthus nigricornis. Behavioral Ecology, 8, 66-74.

Bussière, L. F., Clark, A. P. \& Gwynne, D. T. 2005. Precopulatory choice for cues of material benefits in tree crickets. Behavioral Ecology, 16, 255-259.

Byers, G. W. \& Thornhill, R. 1983. Biology of the Mecoptera. Annual Review of Entomology, 28, 203-228.

Chapman, T., Miyatake, T., Smith, H. K. \& Partridge, L. 1998. Interactions of mating, egg production and death rates in females of the Mediterranean fruit fly, Ceratitis capitata. Proceedings of the Royal Society B, 265, 1879-1894.

Cotton, S., Small, J. \& Pomiankowski, A. 2006. Sexual selection and conditiondependent mate preferences. Current Biology, 16, R755-R765.

Dewsbury, D. A. 1982. Ejaculate cost and male choice. American Naturalist, 119, 601-610.

Elwood, R. W. \& Dick, J. T. A. 1990. The amorous Gammarus: the relationship between precopula duration and size-assortative mating in G. pulex. Animal Behaviour, 39, 828-833.

Engels, S. \& Sauer, K. P. 2006. Resource dependent nuptial feeding in Panorpa vulgaris: an honest signal of male quality. Behavioral Ecology, 17, 628-632.

Engqvist, L. 2005. The mistreatment of covariate interaction terms in linear model analyses of behavioural and evolutionary ecology studies. Animal Behaviour, 70, 967-971.

Engqvist, L. 2007a. Male scorpionflies assess the amount of rival sperm transferred by females' previous mates. Evolution, 61, 1489-1494.

Engqvist, L. 2007b. Nuptial food gifts influence female egg production in the scorpionfly Panorpa cognata. Ecological Entomology, 32, 327-332.

Engqvist, L. 2007c. Nuptial gift consumption influences female remating in a scorpionfly: male or female control of mating rate? Evolutionary Ecology, 21, 49-61.

Engqvist, L. 2007d. Sex, food and conflicts: nutrition dependent nuptial feeding and pre-mating struggles in scorpionflies. Behavioral Ecology and Sociobiology, 61, 703-710.

Engqvist, L. \& Sauer, K. P. 2001. Strategic male mating effort and cryptic male choice in a scorpionfly. Proceedings of the Royal Society B, 268, 729-735.

Engqvist, L. \& Sauer, K. P. 2002a. Amorous scorpionflies: causes and consequences of the long pairing prelude of Panorpa cognata. Animal Behaviour, 63, 667-675.

Engqvist, L. \& Sauer, K. P. 2002b. A life history perspective on strategic mating effort in male scorpionflies. Behavioral Ecology, 13, 632-636.

Engqvist, L. \& Sauer, K. P. 2003a. Determinants of sperm transfer in the scorpionfly Panorpa cognata: male variation, female condition and copulation duration. Journal of Evolutionary Biology, 16, 1196-1204.

Engqvist, L. \& Sauer, K. P. 2003b. Influence of nutrition on courtship and mating in the scorpionfly Panorpa cognata. Ethology, 109, 911-928.

Engqvist, L., Dekomien, G., Lippmann, T., Epplen, J. T. \& Sauer, K. P. 2007. Sperm transfer and paternity in the scorpionfly Panorpa cognata: large variance in traits favoured by postcopulatory episodes of sexual selection. Evolutionary Ecology, 21, 801-816.
Fox, G. A. 2001. Failure-time analysis: emergence, flowering, survivorship, and other waiting times. In: Design and Analysis of Ecological Experiments (Ed. by S. M. Scheiner \& J. Gurevitch), pp. 253-289. Oxford: Oxford University Press.

Grafen, A. \& Ridley, M. 1983. A model of mate guarding. Journal of Theoretical Biology, 102, 549-567.

Gwynne, D. T. 2008. Sexual conflict over nuptial gifts in insects. Annual Review of Entomology, 53, 83-101.

Hunt, J., Brooks, R. \& Jennions, M. D. 2005. Female mate choice as a conditiondependent life-history trait. American Naturalist, 166, 79-92.

Jennions, M. D. \& Petrie, M. 1997. Variation in mate choice and mating preferences: a review of causes and consequences. Biological Reviews of the Cambridge Philosophical Society, 72, 283-327.

Johnstone, R. A. 1995. Sexual selection, honest advertisement and the handicap principle: reviewing the evidence. Biological Reviews, 70, 1-65.

Johnstone, R. A., Reynolds, J. A. \& Deutsch, J. C. 1996. Mutual mate choice and sex differences in choosiness. Evolution, 50, 1382-1391.

Jones, I. L. \& Hunter, F. M. 1993. Mutual sexual selection in a monogamous seabird. Nature, 362, 238-239.

Jormalainen, V. 1998. Precopulatory mate guarding in crustaceans: male competitive strategy and intersexual conflict. Quarterly Review of Biology, 73, 275-304.

Kock, D., Ruther, J. \& Sauer, K. P. 2007. A male sex pheromone in a scorpionfly. Journal of Chemical Ecology, 33, 1249-1256.

Kraak, S. B. M. \& Bakker, T. C. M. 1998. Mutual mate choice in sticklebacks: attractive males choose big females, which lay big eggs. Animal Behaviour, 56, 859-866.

Lehmann, G. U. C. \& Lehmann, A. W. 2008. Bushcricket song as a clue for spermatophore size? Behavioral Ecology and Sociobiology, 62, 569-578.

Leopold, R. A. 1976. The role of male accessory glands in insect reproduction. Annual Review of Entomology, 21, 199-221.

Milinski, M. \& Bakker, T. C. M. 1992. Costs influence sequential mate choice in sticklebacks, Gasterosteus aculeatus. Proceedings of the Royal Society B, 250, 229-233.

Parker, G. A. 1974. Courtship persistence and female-guarding as male time investment strategies. Behaviour, 48, 157-184.

Parker, G. A. \& Simmons, L. W. 1989. Nuptial feeding in insects: theoretical models of male and female interests. Ethology, 82, 3-26.

Proctor, H. C. 1998. Indirect sperm transfer in arthropods: behavioral and evolutionary trends. Annual Review of Entomology, 43, 153-174.

R Development Core Team. 2008. R: a Language and Environment for Statistical Computing. Vienna: R Foundation for Statistical Computing.

Real, L. 1990. Search theory and mate choice. I. Models of single-sex discrimination. American Naturalist, 136, 376-404.

Reinhold, K., Reinhold, K. \& Jacoby, K. J. 2002. Dissecting the repeatability of female choice in the grasshopper Chorthippus biguttulus. Animal Behaviour, 64, $245-250$.

Rowe, L. \& Houle, D. 1996. The lek paradox and the capture of genetic variance by condition dependent traits. Proceedings of the Royal Society B, 263, 1415-1421.

Sauer, K. P. 1970. Zur Monotopbindung einheimischer Arten der Gattung Panorpa (Mecoptera) nach Untersuchungen im Freiland und im Laboratorium. Zoologische Jahrbücher: Abteilung für Systematik, Ökologie und Geographie der Tiere, 97, 201-284.

Sauer, K. P. 1977. The adaptive significance of genetic variability of photoperiodic response in Panorpa vulgaris. Zoologische Jahrbücher: Abteilung für Systematik, Ökologie und Geographie der Tiere, 104, 489-538.

Schaller, F. 1971. Indirect sperm transfer by soil arthropods. Annual Review of Entomology, 16, 407-446.

Simmons, L. W. \& Gwynne, D. T. 1991. The refractory period of female katydids (Orthoptera: Tettigonidae): sexual conflict over the remating interval? Behavioral Ecology, 2, 276-282.

Simmons, L. W., Llorens, T., Schinzig, M., Hosken, D. \& Craig, M. 1994. Sperm competition selects for male mate choice and protandry in the bushcricket, Requena verticalis (Orthoptera: Tettigonidae). Animal Behaviour, 47, 117-122.

Stockley, P. 1997. Sexual conflict resulting from adaptations to sperm competition. Trends in Ecology \& Evolution, 12, 154-159.

Svärd, L. \& Wiklund, C. 1988. Prolonged mating in the monarch butterfly Danaus plexippus and nightfall as a cue for sperm transfer. Oikos, 52, 351-354.

Therneau, T. M. \& Grambsch, P. M. 2004. Modeling Survival Data: Extending the Cox Model. New York: Springer.

Thornhill, R. 1979. Male pair-formation pheromones in Panorpa scorpionflies (Mecoptera: Panorpidae). Environmental Entomology, 8, 886-888.

Thornhill, R. \& Sauer, K. P. 1992. Genetic sire effects on the fighting ability of sons and daughters and mating success of sons in a scorpionfly. Animal Behaviour, $\mathbf{4 3}$, 255-264.

Watson, P. J.1991. Multiple paternity and first mate sperm precedence in the sierra dome spider Linyphia litigosa (Linyphiidae). Animal Behaviour, 41, 135-148.

Wedell, N. 2005. Female receptivity in butterflies and moths. Journal of Experimental Biology, 208, 3433-3440.

Wedell, N., Gage, M. J. G. \& Parker, G. A. 2002. Sperm competition, male prudence and sperm-limited females. Trends in Ecology E Evolution, 17, 313-320. 